\title{
Interactive comment on "Relative impacts of global changes and regional watershed changes on the inorganic carbon balance of the Chesapeake Bay” by Pierre St-Laurent et al.
}

\section{Pierre St-Laurent et al.}

pst-laurent@vims.edu

Received and published: 26 May 2020

We thank the referee for their careful reading of the manuscript and for providing helpful and thoughtful comments. Referees' comments are italicized while the Authors' responses are not italicized.

The manuscript describes a model sensitivity experiment assessing the impacts of atmospheric carbon dioxide, water temperature and riverine nitrogen, carbon and alkalinity on the inorganic carbon budget of Chesapeake Bay. Model sensitivity experiments are an essential tool for understanding the individual and combined impacts of differ- 
ent components of complex non-linear systems. The experiment is well designed. The modelling system used is based on an established published model; modifications for the current work are clearly described and model validation is included. The result that the two global changes (temperature and $\mathrm{CO} 2$ concentrations) have opposite impacts on air-sea $\mathrm{CO} 2$ flux is expected, but the experiments also show mitigating impacts on DIC export and Net Ecosystem Production and give estimates of all magnitudes. Likewise, the impacts of two regional changes (riverine nitrogen and carbon loads) partially mitigate changes in air-sea CO2 fluxes and NEP. The results are interesting and give an insight into the likely future carbon budget in Chesapeake Bay. The manuscript is well written and structured, with appropriate figures and tables.

In the sensitivity experiments, the meteorological forcing is the same as the control simulation (early 2000s) and the water temperature and riverine DIC and alkalinity experiments use values estimated from mid 20th century data. To avoid any confusion for the reader, it would be useful to reinforce (perhaps in the conclusion section) that the sensitivity experiments are not modelling actual early 1900 s conditions.

The referee makes a very good point. We propose to insert the following statement in Section "Summary and Concluding remarks":

“... experiments were performed to isolate the effect of changes in: (1) atmospheric $\mathrm{CO} 2$, (2) temperature, (3) riverine nitrogen loading and (4) riverine carbon and alkalinity loading, on the inorganic carbon balance of the Chesapeake Bay between the early 1900's and early 2000's. Limited information is available for the early 1900's and thus these experiments are meant to highlight the aforementioned changes rather than to model actual early 1900's conditions. Both regional and global changes..."

Printer-friendly version

One technical correction: the labels of figure $3 b$ refer to TIC; DIC is used in the caption.

Discussion paper 
We apologize for this oversight. The figure will be corrected accordingly in the revision of the manuscript.

Interactive comment on Biogeosciences Discuss., https://doi.org/10.5194/bg-2020-117, 2020. 